\title{
EL FUNDAMENTO JURÍDICO DE UN DERECHO DE NECESIDAD
}

\author{
Andrés Bouzat * \\ Alejandro S. Cantaro ** \\ Pablo E. Navarro***
}

\section{Introducción}

Las causas de justificación pretenden corregir el excesivo alcance de los tipos penales ${ }^{1}$, aunque no siempre sea fácil determinar si un precepto jurídico tiene que entenderse como una excusa o una justificación ${ }^{2}$. Esta dificultad no es tanto el resultado de una deficiente técnica legislativa

* Profesor de Filosofía del Derecho y Derecho Político (Universidad Nacional del Sur, Bahía Blanca).

** Profesor de Derecho Penal I y Derecho Penal II (Universidad Nacional del Sur, Bahía Blanca).

*** CONICET, Profesor de Filosofía del Derecho (Universidad Nacional del Sur, Bahía Blanca). ${ }^{1}$ Siguiendo la terminología empleada por Schauer es usual señalar que las causas de justificación pretenden corregir la sobre-inclusión de las reglas penales. Al respecto, véase: Schauer, Frederick, Playing by the Rules, pp. 39-47 (Oxford: Oxford University Press). Para una aplicación de las categorías de Schauer al derecho penal, véase: Ferreres, Víctor, El principio de taxatividad en materia penal y el valor normativo de la jurisprudencia, pp. 34-37 (Madrid: Civitas, 2002); Moreso, José Juan, 'Principio de legalidad y causas de justificación' en Doxa 24 (2001), pp. 534 y ss

${ }^{2}$ Las diferencias entre excusa y justificación constituyen uno de los rasgos básicos del discurso moral. Una excusa constituye el reconocimiento de una infracción y pretende disminuir o cancelar el reproche. Por el contrario, una justificación es una manera de defender la corrección de una conducta, aun en casos en que la misma pueda ser considerada 
como el producto del desarrollo histórico y contingente de las justificaciones en el derecho penal. Por ejemplo, aunque ya antiguamente se reconoce a la legítima defensa como una justificación, hay divergencias significativas en el modo en que esa justificación se configura en el derecho contemporáneo, i.e. diferencias respecto de quienes tienen derecho a repeler una agresión, las circunstancias en que la defensa es legítima, los medios que se pueden utilizar, el reproche en caso de excesos y el valor de los bienes que se protegen.

En el caso del estado de necesidad, las dificultades conceptuales son aún mayores ya que, como señala Fletcher, 'la característica más notable del estado de necesidad como justificación es su relativa modernidad'?. En tanto que justificación, el estado de necesidad compromete con dos consecuencias: por una parte, quien emprende una conducta salvadora en el marco de ese tipo de situaciones se comporta de manera jurídicamente correcta y, por otra parte, la fuerza justificatoria se expande hacia las acciones que cooperan, alientan o promueven la conducta salvadora. Sin embargo, una adecuada reconstrucción del estado de necesidad ofrece todavía muchos aspectos desconcertantes. Por ejemplo, ¿son relevantes las actitudes subjetivas de los agentes a los efectos de evaluar si se aplica una causa de justificación? ${ }^{4}$ Al respecto, Carlos

a primera vista como ilegítima. Para una exposición de estas dificultades, véase, por ejemplo: Austin, John, 'A Plea for Excuses' en Philosophical Papers, 2a edición, pp. 175-204 (Oxford: Oxford University Press, 1970); Hart, H.L.A., 'Legal Responsibility and Excuses' en Punishment and Responsibility, pp. 28-53 (Oxford: Oxford University Press, 1968); Bacigalupo, Enrique, Delito y punibilidad, $2^{\mathrm{a}}$ edición, pp. 107 y ss (Buenos Aires: Hammurabi, 1999); Silva Sánchez, Aproximaciones al derecho penal contemporáneo, pp. 408 y ss (Barcelona: PPU, 1992)

${ }^{3}$ Fletcher, George, Conceptos básicos en el derecho penal, p. 207 (Valencia: Tirant Lo Blanc, 1997); Soler, Sebastián, Derecho Penal Argentino, § 33, pp. 419-420 (Buenos Aires: Tipográfica editora argentina, 1956)

${ }^{4}$ Mir Puig, Santiago, Derecho Penal. Parte General, $5^{\text {a } e d i c i o ́ n, ~, ~ p p . ~ 469-470 ~(B a r c e l o n a: ~}$ REPPERTOR, 1998) 
Nino sostiene ${ }^{5}$ :

...supongamos que alguien tira una piedra contra un vidrio con la intención de perjudicar a su dueño y, por casualidad, lo salva así de morir asfixiado por un escape de gas. ¿Está la acción justificada? Creo que la respuesta debe ser afirmativa una vez que se toma en cuenta que sería correcta una acción que cooperara con ella e incorrecta una acción que la obstaculizase.

Mientras Nino afirma que las actitudes subjetivas son irrelevantes para evaluar la justificación de una conducta, Carmen Argibay sostiene' ${ }^{6}$.

$\mathrm{Si}$, por mera intención de dañar, alguien arroja una piedra contra la vidriera de un comercio haciendo sonar la alarma, lo cual posibilita la detención de quienes intentaban asaltar el negocio, esta acción no está encuadrada en la causa de justificación pues no aparece el elemento subjetivo indispensable para poder hacerlo.

Otro importante tema de debate se refiere al modo en que impactan en bienes ajenos las conductas que se despliegan bajo la protección de una causa de justificación. Una valiosa contribución al análisis de este problema es el artículo 'Derechos de necesidad agresiva y deberes de tolerancia' del profesor Silva Sánchez, que abre la discusión de este volumen?7. En su trabajo, Silva Sánchez analiza si las conductas que se emprenden en situación de estado de necesidad justificante constituyen el ejercicio de un derecho de intromisión y, correlativamente, si los individuos afectados por esa conducta tienen el deber de tolerarla. Su conclusión es

${ }^{5}$ Nino, Carlos, Introducción a la filosofía de la acción humana, p. 113 (Buenos Aires: Eudeba, 1987)

${ }^{6}$ Argibay, Carmen, 'Artículo 34, inciso 3. Estado de necesidad justificante' en Baigún, David, et al. Código Penal Comentado. Tomo I, p. 630 (Buenos Aires: Hammurabi, 1997)

7 Silva Sánchez, Jesús, M., 'Derechos de necesidad agresiva y deberes de tolerancia' en DISCUSIONES 
afirmativa y defiende que en el derecho de los Estados modernos existe un derecho de necesidad y un correlativo deber de tolerancia.

En este trabajo mostraremos que aun cuando la propuesta de Silva Sánchez subraye importantes aspectos de nuestro discurso moral acerca del derecho, sus argumentos no distinguen con suficiente claridad entre la descripción y la crítica del derecho penal. Por esa razón, nuestra conclusión será que sus tesis centrales tienen que ser revisadas.

\section{Derecho de necesidad y deber de tolerancia}

En diversos pasajes de la introducción de su trabajo, Silva Sánchez asume una conexión entre un derecho de necesidad y un deber de tolerancia. El derecho de necesidad tendría un correlato lógico en el deber de tolerancia, y la existencia de este deber sería una suerte de 'prueba' de que se reconoce un genuino derecho de necesidad. Sin embargo, no hay en su trabajo un argumento específico a favor de tal conexión. Por el contrario, en la teoría del derecho contemporánea es usual asumir que sólo en algún sentido de 'derecho' y en algún sentido de 'deber', ambas posiciones jurídicas se encuentran conectadas de manera tan fuerte. Por ejemplo, las relaciones entre esas posiciones se alterarían sustancialmente si se concibe a los derechos de necesidad en términos de libertades hohfeldianas (también denominados privilegios) ${ }^{8}$. Podría decirse, por ejemplo, que la persona que actúa en estado de necesidad no ejerce un derecho subjetivo sino una libertad. La persona afectada por la acción del necesitado se encuentra en una situación de no derecho: no tiene derecho a interferir con la acción del necesitado. Pero de allí no se sigue que tenga el deber jurídico de no interferir, y mucho menos que tenga el deber jurídico de colaborar con la acción del necesitado. En este caso se enfrenta una persona -el necesitado- que tiene la libertad de, por ejemplo,

\footnotetext{
${ }^{8}$ Hohfeld, W.N., Conceptos jurídicos fundamentales (Buenos Aires: Centro Editor de América Latina, 1968).
} 
usar el bien $x$, con otra persona -el propietario- que tiene el derecho de usarlo. La libertad de usar el bien $x$ que se le confiere al necesitado desplaza su deber general de no hacerlo, pero no alcanza a configurar un derecho a usar $x$ (que genere un deber correlativo al propietario). En muchas ocasiones, la naturaleza justificada de una acción, y el 'derecho' que de allí se deriva, solo implica que no puede ser penada. Pero ello no significa que cualquier interferencia con la realización de la misma deba ser castigada. Por ejemplo, podemos estar frente a dos acciones facultativas, que no generan deberes correlativos. En este sentido, es ilustrativo el siguiente ejemplo de Genaro Carrió acerca de las posiciones jurídicas en que se encuentran dos boxeadores 9 :

No cabe duda de que las reglas del boxeo no prohíben que $\mathrm{A}$ aseste a $\mathrm{B}$ un impecable golpe de puño en la mandíbula. Lejos de ello, el esfuerzo de A en tal sentido parece corresponder claramente al espíritu del deporte y A está autorizado expresamente a hacerlo. Es más, las reglas del mismo lo estimulan a comportarse así. Pero aunque las reglas del boxeo autorizan a A a dar golpes 'correctos' a B, sería indudablemente falso decir que A tiene el derecho de golpear así a B... A no tiene ese derecho, por la sencilla razón de que sería no solo falso, sino absurdo, sostener que B tiene el deber de no impedir que A le dé golpes de esa clase.... Es obvio que la terminología de derechos y deberes, en el sentido definido, fracasa totalmente para dar cuenta de la recíproca situación normativa de nuestros dos púgiles a la luz de las reglas del boxeo. No se trata de que esa terminología refleje inadecuadamente o distorsione la cosas; simplemente no funciona en absoluto.

\footnotetext{
${ }^{9}$ Carrió, Genaro, 'Nota preliminar' en Hohfeld, W.N., Conceptos jurídicos fundamentales, pp. 16-17 (Buenos Aires: Centro Editor de América Latina, 1968). Para una refinada reconstrucción formal de las categorías de Hohfeld, véase: Lindahl, Lars, Position and Change. A Study in Law and Logia (Dordrecht: Reídle, 1977). Para una generalización que trasciende las categorías de Hohfeld y que mantiene la consistencia de atribuir un derecho a X y, simultáneamente, imponer un deber de no hacer X, véase: Enoch, David, 'A Right to Violate One's Duty' en Law and Philosophy 21 (2002), pp. 355-384.
} 
En igual sentido, en un estudio sobre la naturaleza de las normas y la posibilidad de una lógica deóntica, Alf Ross sostenía ${ }^{10}$ :

Finalmente, es un error introducir 'derecho' como correlato de 'deber'. El concepto de derecho es un concepto sistemático en el que se unen un cierto número de normas jurídicas, y cubre una serie de efectos jurídicos cada uno de los cuales puede expresarse en las modalidades mencionadas. Por ejemplo, el derecho de propiedad incluye un conjunto de pretensiones, libertades, competencias e inmunidades. Un 'derecho'... no es una modalidad jurídica usada en la expresión de una norma jurídica particular, sino una construcción teórica que sirve para la presentación sistemática del derecho vigente.

Esta cautela acerca del uso de las expresiones 'derecho' y 'deber' no pretende negar que, en algunas ocasiones, la existencia de un deber sea el reflejo de un determinado derecho ${ }^{11}$. Más bien, intentamos señalar que éste es también un punto controvertido y que no debe darse por supuesto que en el caso de las conductas justificadas por el estado de necesidad existe tal relación entre derechos y deberes. Sin embargo, un análisis detallado de este tema excede los límites de nuestro trabajo $\mathrm{y}, \mathrm{a}$ efectos de simplificar nuestra exposición, asumiremos que el deber de tolerancia es correlativo del derecho de necesidad.

${ }^{10}$ Ross, Alf, Directives and Norms, pp. 134-135 (Londres: Routledge \& Kegan Paul, 1968) ${ }^{11}$ Para un análisis contemporáneo de derechos como correlativos de deberes, véase: Raz, Joseph, 'Legal Rights' en Ethics in the Public Domain, pp. 238-260 (Oxford: Oxford University Press, 1994). El núcleo de su doctrina es el siguiente (p. 252): 'Un individuo tiene un derecho si un interés suyo es suficiente para imponer a otro un deber. Su derecho es jurídico si es reconocido por el derecho, es decir si el derecho garantiza que su interés es un fundamento suficiente para someter a otros a un deber'. A su vez, Hart considera que un estudio detallado de Bentham ofrece una guía más atractiva para el estudio de los derechos que las consideraciones de Hohfeld. Véase: Hart, H.L.A., 'Legal Rights' en Essays on Bentham, pp. 162-193 (Oxford: Oxford University Press, 1982) 


\section{Identificación del derecho y fundamentos jurídicos}

Es común asumir que si un argumento únicamente contiene premisas morales, no puede justificar una conclusión jurídica. Entre otras cosas, esto significa que los fundamentos jurídicos y morales de los derechos tienen diferente naturaleza. Mientras que los primeros tienen un apoyo institucional, los segundos dependen de argumentos sustantivos. Al respecto, Joseph Raz señala12:

Para establecer la verdad de un enunciado jurídico, no se tiene que establecer que su contenido es verdadero sino que tiene status jurídico, que tiene fuerza jurídica. Justificar un enunciado jurídico no tiene que confundirse con probar o establecer su verdad.

Silva Sánchez comparte esta distinción y, al finalizar la introducción de su trabajo, afirma (sección 1):

... el deber de tolerancia del afectado y de otros terceros no se deriva sin más del carácter no prohibido de la conducta justificada, sino que su fuente debe de hallarse en una norma adicional. La cuestión es determinar la fuente del deber de tolerancia de terceros con respecto a la conducta realizada en estado de necesidad agresivo. Si se trata simplemente de un deber moral o de un deber jurídico y, más concretamente, jurídico-penal.

A efectos de identificar en qué consiste un fundamento jurídico es preciso recordar brevemente algunas ideas básicas acerca del derecho y los enunciados jurídicos. El derecho de una comunidad puede ser considerado como el conjunto normativo que los jueces pueden invocar para justificar sus decisiones. Este conjunto normativo se identifica a partir de circunstancias contingentes o rasgos fácticos que varían de comunidad a comunidad. Por ejemplo, los jueces españoles no pueden,

${ }^{12}$ Raz, Joseph, 'Legal Rights' en Ethics in the Public Domain, op. cit., p. 245 
salvo circunstancias específicamente estipuladas, invocar lo que ha decidido el legislador argentino como justificación de sus decisiones. Aunque ocasionalmente los jueces españoles puedan dejar de lado las decisiones del parlamento español, siempre tienen que invocar otra razón jurídica que justifique ese apartamiento. Por el contrario, estos jueces no necesitan invocar ninguna razón para no aplicar las normas del derecho argentino. Incluso cuando las normas de otros ordenamientos extranjeros sean más justas o eficientes, los jueces no pueden aplicarlas y no necesitan justificación para dejarlas de lado.

Las leyes no describen conductas sino que expresan decisiones de las autoridades normativas. En tanto que esas decisiones sean las pautas que exclusivamente cuentan como derecho en un cierto dominio normativo, nada garantiza la coincidencia entre las exigencias jurídicas y los ideales morales. Cualquier legislador puede equivocarse en sus decisiones y obligar o prohibir conductas que no tienen justificación a la luz de la moral crítica. Los jueces no pueden justificar sus decisiones en aquellas pautas que los legisladores deberían haber adoptado, sino en aquellas normas que han sido expresamente formuladas por las autoridades. Las pautas morales o las prácticas sociales que no han sido reconocidas por el legislador se encuentran en idéntica situación que las normas promulgadas por una autoridad extranjera: los jueces no pueden fundar sus decisiones en esos conjuntos normativos y no precisan ninguna justificación para dejarlos de lado.

Esta independencia conceptual entre derecho y moral no excluye otras relaciones relevantes entre ambos dominios normativos. En ciertas ocasiones la autoridad remite expresa o implícitamente a normas y principios morales. Por ejemplo, un legislador regula el comportamiento mediante expresiones cargadas de connotaciones valorativas y ello exige el desarrollo de un argumento moral para identificar su alcance. Sin embargo, en última instancia, siempre tiene sentido preguntarse acerca de qué norma debería ser derogada a efectos de evitar que un juicio moral específico se convierta en fundamento de un cierto enunciado jurídico. 
Por ejemplo, en Argentina el delito de estupro se refería a una relación sexual con una mujer honesta de entre doce y quince años. Esta figura penal originó cierta controversia en la doctrina y discrepancias en la jurisprudencia acerca de su aplicación a las prostitutas que tenían la edad estipulada. Para algunos jueces, el ejercicio de la prostitución impedía el desarrollo de una vida honesta, mientras que otros magistrados defendían una posición más liberal sobre este problema. De todos modos, tanto quienes defendían la aplicación de esa norma como los que la rechazaban desarrollaban argumentos morales, que constituían la base de la solución jurídica que proponían. Por ello, las convicciones morales constituían parte de los fundamentos jurídicos que se ofrecían en esos casos. Sin embargo, si el legislador hubiese decidido evitar la influencia de estos juicios morales podría haber derogado esa norma y, de ese modo, las convicciones morales acerca de la honestidad de la prostitución hubieran perdido completamente su relevancia para determinar la solución jurídica de una controversia ${ }^{13}$. Más adelante volveremos sobre las conexiones entre la eliminación de normas y los fundamentos de verdad de los enunciados jurídicos. Ahora únicamente subrayaremos que las normas morales, al igual que el derecho extranjero, pueden ser invocadas como justificación de una decisión sólo si las normas expresamente formuladas así lo establecen ${ }^{14}$.

${ }^{13}$ Acerca de la aplicabilidad de las normas que no son válidas en el sistema jurídico, véase: Bulygin, Eugenio, 'Tiempo y validez' en Alchourrón, Carlos y Bulygin, Eugenio, Análisis lógico y derecho, pp. 195-214 (Madrid: Centro de Estudios Constitucionales, 1991); ‘Algunas consideraciones sobre los sistemas jurídicos' en Doxa 9 (1991), pp. 257-279; Navarro, Pablo y Moreso, José Juan, ‘Aplicabilidad y eficacia de las normas jurídicas’ en Isonomía 5 (1996), pp. 119-139; Navarro, Pablo et al. 'La aplicabilidad de los sistemas jurídicos' en Analisi e Diritto 2000, pp. 133-152.

${ }^{14}$ Esta reconstrucción de las relaciones entre derecho y moral es característica del denominado positivismo jurídico excluyente, defendido por autores como Joseph Raz o Andrei Marmor. Para una presentación de este enfoque, véase: Marmor, Andrei, 'Exclusive Legal Positivism' en Positive Law and Objective Values, pp. 49-70 (Oxford: Oxford University Press, 2001) 


\section{Normas derivadas y jerarquías normativas}

Si el legislador hubiese reconocido explícitamente un derecho de necesidad, el debate acerca de su jerarquía, alcance y fundamentos jurídicos dependería de esa decisión legislativa y las disputas acerca de la existencia de ese derecho carecerían de mayor interés. Sin embargo, de esta ausencia de fundamentos expresos no se puede concluir lisa y llanamente que no existe ese derecho. Con frecuencia, los juristas respaldan sus afirmaciones acerca del status normativo de una acción en las 'normas implícitas' de un sistema jurídico. Aun cuando ninguna de las normas promulgadas se refiera expresamente a un cierto caso, el razonamiento jurídico identifica consecuencias y soluciones implícitas en el material normativo formulado expresamente por la autoridad ${ }^{15}$. Las características centrales de las normas implícitas en un sistema jurídico son las siguientes ${ }^{16}$ : (i) son normas derivadas, i.e. no han sido expresamente formuladas; (ii) son parte del contenido conceptual de otras normas que han sido promulgadas explícitamente; (iii) dependen de las reglas de inferencia que se emplean al hacer explícito el contenido conceptual de las normas formuladas, (iv) su fundamento sólo puede ser otra norma.

Las normas derivadas se fundamentan conceptualmente en las normas formuladas y ello significa que, en última instancia, el valor de verdad de un enunciado jurídico siempre depende de las normas que ha formulado el legislador. Dado que la verdad de los enunciados jurídicos depende de las normas válidas en un cierto sistema, la eliminación de alguna de esas normas conlleva que determinados enunciados jurídicos ya no puedan

${ }^{15}$ Guastini, Riccardo, Distinguiendo, p. 357 (Barcelona: Gedisa, 1999); véase también: Ernst, Carlos: Derechos implícitos (Córdoba: Lerner, 1994)

16 Bulygin, Eugenio, 'Lógica y normas' en Isonomía 1 (1994), p. 35. También véase: Alchourrón, Carlos y Bulygin, Eugenio, Introducción a la metodología de las ciencias jurídicas y sociales, op. cit. (Versión orginal en inglés, Normative Systems (Wein/New York: Springer Verlag, 1971) 
seguir siendo considerados como verdaderos. Esta relación entre fundamentos jurídicos y normas formuladas sirve para enunciar el siguiente criterio para determinar tanto el fundamento de las normas implícitas como también el valor de verdad de los enunciados jurídicos que se refieren a ellas. Por razones de simplicidad, este criterio será denominado como Test de Fundamento:

Test de Fundamento: identificar el fundamento jurídico de una norma derivada ND es reconocer qué normas tendrían que eliminarse del sistema para que ND dejase de estar implícita en el contenido conceptual de ese sistema normativo.

En caso de que no sea posible indicar las normas que tienen que ser eliminadas para que desaparezca la norma implícita, entonces el enunciado jurídico que se refiere a ND no es verdadero. En el mejor de los casos será un enunciado acerca de lo que debería ser el derecho, pero no es una afirmación verdadera acerca de los derechos y deberes que los individuos tienen efectivamente en un determinado sistema jurídico.

La única manera de lograr que desaparezca una norma derivada de un cierto sistema jurídico es modificando las normas formuladas que la implican ${ }^{17}$. Este resultado puede conseguirse de diferentes modos. En primer lugar, puede derogarse la norma formulada que implica a la norma derivada ya que la norma derivada desaparece cuando se elimina su fundamento jurídico. Para que se produzca este resultado no es necesario que la autoridad normativa conozca o acepte que la derogación de la norma formulada implica la eliminación de la norma derivada. Más bien, es suficiente con que desaparezca la relación de implicación entre normas formuladas y derivadas. En segundo lugar, el legislador puede promulgar expresamente una norma incompatible con la norma derivada. Por aplicación del principio

\footnotetext{
${ }^{17}$ Para una reconstrucción del fenómeno de la eliminación de normas, véase: Alchourrón, Carlos y Bulygin, Eugenio, Sobre la existencia de las normas jurídicas, p. 81 (México: Fontamara, 1997)
} 
Andrés Bouzat - Alejandro S. Cantaro - Pablo E. Navarro

lex posterior, se elimina la norma derivada y para lograr ese resultado se modifica o elimina la norma formulada que la implica.

Es usual admitir, como complemento de la regla lex posterior, que quien tiene competencia para introducir una norma en un cierto sistema jurídico también tiene competencia para eliminarla ${ }^{18}$. Ello implica que el alcance de la regla lex posterior suele estar limitado por el diferente nivel jerárquico de las normas de un sistema jurídico ${ }^{19}$. Ahora bien, ¿qué jerarquía tienen las normas derivadas? Este es un problema que ha recibido insuficiente atención en teoría del derecho ${ }^{20}$. La intuición más simple es que las normas derivadas heredan la jerarquía de las normas que la fundamentan y, conforme a esta idea, se pueden distinguir entre diferentes situaciones:

a) Si una norma implícita ND deriva de una única norma NF, entonces ND tiene un fundamento simple, y su jerarquía es equivalente al rango de NF. Ello significa que para eliminar esa norma implícita es suficiente con la eliminación de NF.

b) Cuando existe un conjunto $\mathrm{CN}$ de normas y cada una de ellas es, por sí misma, suficiente para que se pueda derivar una cierta norma ND puede decirse que ND está sobredeterminada en ese sistema normativo. La jerarquía de ND corresponde a la jerarquía de la norma con mayor

\footnotetext{
${ }^{18}$ Alchourrón, Carlos y Bulygin, Eugenio, Sobre la existencia de las normas jurídicas, op. cit., p. 81

${ }^{19}$ Sin estas reglas no habría dinámica normativa, que es uno de los rasgos característicos que introduce la autoridad jurídica, i.e. la posibilidad de modificar deliberadamente el status normativo de las conductas. Al respecto, véase Alchourrón, Carlos y Bulygin, Eugenio, 'Libertad y autoridad normativa' en Análisis lógico y derecho, pp. 242-243 (Madrid: Centro de Estudios Constitucionales, 1991)

${ }^{20}$ Al respecto, véase: Navarro, Pablo y Redondo, María Cristina, 'Permisiones y actitudes normativas' en Doxa 7 (1990), pp. 249-256, 'Derogation, Logical Indeterminacy and Legal Expressivism' en Rechtstheorie 21 (1990), pp. 233-239. También, Navarro, Pablo, 'Promulgation and Derogation of Legal Rules' en Law and Philosophy 12 (1993), pp. 385-394.
} 
rango del conjunto $\mathrm{CN}$ ya que ND sólo es eliminada cuando se deroga a esa norma que la fundamenta. Por ejemplo, supongamos que el legislador ordinario repite en sus leyes, algunos derechos o garantías implícitos en las disposiciones constitucionales. En este caso, la derogación de la ley no implica la eliminación del derecho o garantía constitucional en cuestión.

c) Cuando una norma ND se deriva de la conjunción de varias normas formuladas puede afirmarse que ND tiene un fundamento complejo. En este caso, todas las normas que implican a la norma derivada son disyuntivamente necesarias y conjuntamente suficientes para la implicación, i.e. cada norma contribuye a la derivación de ND. La jerarquía de la norma derivada depende del rango de las normas que forman su fundamento complejo. En este caso, hay que considerar dos posibilidades:

(i) Si todas esas normas tienen un mismo nivel jerárquico (e.g. rango de ley), entonces ND hereda ese rango en el sistema.

(ii) Si las normas han sido formuladas por autoridades de diferente rango, entonces la jerarquía de la norma derivada corresponde a la norma de menor jerarquía que fuese necesaria para implicar a la norma derivada.

Las normas que no pueden ser eliminadas deliberadamente no forman parte del sistema jurídico. No existen 'normas necesarias' en el derecho positivo (i.e. 'derecho puesto por las autoridades'). Esta reconstrucción excluye que una norma que no ha sido formulada por la autoridad normativa y que no se deriva de ninguna otra norma del sistema pueda ser invocada como justificación de una decisión. Esta consecuencia es el compromiso asumido mediante el Test de Fundamento introducido anteriormente. Su principal utilidad es ayudarnos a comprender claramente cuándo una afirmación sobre la calificación de una acción tiene fundamento jurídico y cuándo es sólo una expresión de nuestros ideales morales acerca de lo que debería contener el derecho. En la siguiente sección analizaremos algunas consecuencias que este enfoque tiene para la solución del problema de los derechos de necesidad. 


\section{La jerarquía del derecho de necesidad}

Si el derecho de necesidad tuviese un fundamento simple, e.g. si únicamente derivase de las causas de justificación reconocidas por el Código Penal, entonces tendría una jerarquía idéntica a las disposiciones legales que la fundamentan. En este caso, el fundamento jurídico del derecho de necesidad sería claro ya que, conforme al Test de Fundamento, para eliminar este derecho de necesidad habría que derogar esa causa de justificación, e.g. artículo 20, inciso 5 del Código Penal Español o artículo 34, inciso 3 del Código Penal Argentino ${ }^{21}$. Cuando el derecho de necesidad se deriva de una norma con jerarquía de ley, ello significa que otras normas de inferior jerarquía no pueden modificar esa relación normativa. Pero también es preciso advertir que el rango de ley del estado de necesidad no puede modificar otras relaciones establecidas por normas superiores a las del Código Penal. En este sentido, parece estar fuera de discusión que las normas que expresa una ley no pueden modificar los derechos y garantías establecidas por la constitución. Dado que la mayoría de los bienes afectados por las conductas emprendidas por quien se encuentra en estado de necesidad están expresamente protegidos por disposiciones constitucionales específicas (e.g. la propiedad, la libertad, la salud, etc.), urge resolver este problema de supremacía y fundamento ${ }^{22}$. De otro modo, el alcance del derecho de necesidad se encontraría seriamente limitado por nuestros compromisos constitucionales.

${ }^{21}$ Puede haber otras normas que impliquen el deber de tolerancia y, en ese caso, el valor de verdad del enunciado jurídico se encuentra sobredeterminado. En casos de sobredeterminación normativa, mientras no se eliminen a todas las normas que son suficientes para implicar a la norma derivada, esa norma implícita seguirá fundamentando la verdad de los enunciados jurídicos acerca del deber de tolerancia.

22 Por ejemplo, la Constitución Argentina señala en su artículo 17: La propiedad es inviolable, y ningún habitante de la Nación puede ser privado de ella, sino en virtud de sentencia fundada en ley. 
En el sistema jurídico español, el artículo 18.2 de la Constitución Española señala:

El domicilio es inviolable. Ninguna entrada o registro podrá hacerse en él sin consentimiento del titular o resolución judicial, salvo caso de flagrante delito.

Imaginemos que un individuo A se encuentra en situación de necesidad. Por ejemplo, A es perseguido por un perro rabioso y su única manera de evitar al animal es irrumpir en el domicilio de su vecino B. Asumamos también que la única forma en que B puede ayudar a su vecino $\mathrm{A}$ es dejándolo ingresar a su vivienda. Este individuo no desea que A ingrese a su vivienda y cierra con llave la puerta. En este caso, ¿prevalece el derecho de necesidad y el correlativo deber de tolerancia, que tienen fundamento legal, sobre el rango constitucional de la inviolabilidad de domicilio ${ }^{23}$ El universo de propiedades relevantes que ha seleccionado el constituyente para regular el acceso a un domicilio sólo menciona a tres propiedades: consentimiento del titular, autorización judicial, y delito flagrante. El caso de individuos que se encuentran en estado de necesidad no está contemplado en la formulación del constituyente ni puede derivarse lógicamente de ella. Por tanto, al expresar el artículo 18.2 una expectativa constitucional de rango superior, el deber legal de $\mathrm{B}$ de tolerar la irrupción de A en su domicilio no prevalece sobre la garantía constitucional de la inviolabilidad del domicilio.

En un texto introductorio a la teoría del derecho, Moreso y Vilajosana analizan las consecuencias de la selección que el constituyente

\footnotetext{
${ }^{23}$ En nuestro ejemplo hemos asumido que el ingreso al domicilio de B es el único curso salvador idóneo para A y la única manera en que B puede colaborar en esa situación. En caso de que B pudiese hacer otra cosa, e.g. disparar sobre el animal rabioso, podría ser verdad que no tuviese el deber de dejar ingresar al individuo A en su domicilio y, al mismo tiempo, su conducta podría verse como una infracción al deber de socorro establecido expresamente en los Códigos Penales contemporáneos.
} 
hace de las características relevantes para ingresar válidamente en un domicilio y señalan ${ }^{24}$ :

... se ha sugerido alguna vez que el artículo 18.2 de la Constitución establece únicamente una pauta no concluyente porque hay otros casos, como el estado de necesidad (por ejemplo: un niño pequeño se ha quedado atrapado en un incendio en cierto domicilio), en donde también es facultativa la entrada en el domicilio (o incluso obligatoria). Si fuera así, entonces el universo de propiedades no estaría clausurado, sería un universo abierto. Ahora bien, al menos para este tipo de casos, puede argumentarse que es plausible incluirlos en la propiedad 'consentimiento del titular', ya que dicho consentimiento puede ser expreso o tácito (parece plausible argüir que tácitamente consentimos en que entren en nuestro domicilio para salvar de un incendio a nuestro hijo pequeño).

A diferencia del ejemplo propuesto por Moreso y Vilajosana, en el ejemplo que hemos imaginado de un individuo que niega la entrada en su domicilio a su vecino perseguido por un perro rabioso, no es posible sostener que hay consentimiento tácito. Por el contrario, el propietario del inmueble ha denegado expresamente el ingreso a su vivienda ${ }^{25}$.

Podría sostenerse que es necesario interpretar correctamente al artículo 18.2 a efectos de resolver el problema mencionado. Pero, ¿qué razones podrían invocarse para defender esta necesidad interpretativa? En esta disposición de la $\mathrm{CE}$, el constituyente ha empleado un vocabulario claro y preciso y el hecho de que sus decisiones no resuelvan ciertas

\footnotetext{
${ }^{24}$ Moreso, José Juan y Vilajosana, Jose María, Introducción a la teoría del derecho, p. 102-103 (Barcelona: Marcial Pons, 2004)

${ }^{25}$ En general, el comportamiento del propietario del inmueble estará guiado por diferentes razones, e.g. tal vez si A ingresa a la casa descubrirá que B esconde cosas robadas y $\mathrm{B}$ quiere evitar eso. Un estudio de esas razones es central tanto para determinar si existe un abuso del derecho de propiedad como así también si la conducta del dueño de la vivienda -quien cree genuinamente que ejerce su derecho de propiedad- está exculpada por un error de prohibición. Acerca del abuso del derecho, véase: Atienza, Manuel y Ruiz Manero, Juan, Ilícitos atípicos, pp. 33-66 (Madrid: Trotta, 2000)
} 
situaciones, o que no las resuelvan del modo en que nosotros preferimos, no es una razón para ignorar lo que ha decidido. Podría responderse que muchas veces el constituyente usa conceptos abstractos, que precisan desarrollo a partir de concepciones específicas (e.g. debido proceso) y en esas situaciones, es necesario elaborar argumentos morales que sirvan para resolver los casos difíciles ${ }^{26}$. Conforme a esta respuesta también podría argumentarse que la protección constitucional del domicilio es un concepto que permanece abierto al desarrollo de diversas concepciones morales y, en particular, el contenido conceptual de la protección constitucional podría limitarse en casos de estado de necesidad. Pero, como señala Dworkin, en otras ocasiones el constituyente escoge limitar específicamente el desarrollo de argumentos morales mediante normas precisas, que imponen una determinada concepción ${ }^{27}$. En estos casos, el constituyente elige -para bien o mal- una cierta manera de resolver problemas normativos. Esta posibilidad es especialmente importante porque sirve para identificar dos maneras diferentes de desafiar la supremacía constitucional. La primera, que suele ser una característica del originalismo $^{28}$, es limitar el contenido de un concepto constitucional a la concepción que el constituyente hubiese favorecido o tenido en mente al momento de elaborarse una constitución. La segunda es tratar a las concepciones específicas que el constituyente ha impuesto para ciertos temas como si fuesen conceptos abiertos a nuevas elaboraciones de su contenido. Por consiguiente, son infieles a la supremacía constitucional aquellos jueces que reemplazan las concepciones que el constituyente ha

26 Dworkin, Ronald, 'Casos constitucionales' en Los Derechos en Serio, op. cit., pp. 215-216.

${ }^{27}$ Dworkin, Ronald, 'Casos constitucionales' en Los Derechos en Serio, op. cit.,p. 211; Dworkin, Ronald, Freedom's Law. The Moral Reading of the American Constitution, p. 8 (Cambridge, Mass: Harvard University Press, 1996)

${ }_{28}$ Acerca del originalismo constitucional, véase: De Lora, Pablo, La interpretación originalista de la constitución (Madrid: Centro de Estudios Constitucionales, 2000) 
escogido e introducen sus propias convicciones -aunque ellas sean más justas, eficientes o se encuentren respaldadas por la dogmática de su comunidad- como respuesta al problema normativo.

Por consiguiente: ¿cómo debemos interpretar el artículo $18.2 \mathrm{CE}$ : como la expresión de un concepto abstracto de domicilio o como una concepción específica? A diferencia de lo que ocurre cuando el constituyente enuncia de manera genérica que los individuos tienen derecho a la educación, a la salud, etc., y reconoce que el contenido de esos derechos se regulará mediante leyes ${ }^{29}$, en el caso del artículo 18.2 se establecen de manera taxativa los alcances de la garantía. Un desarrollo interpretativo de esta disposición equivale, entonces, al cambio del alcance de esta garantía constitucional. Al respecto, Bulygin afirma ${ }^{30}$ :

Es verdad de que no sucede con frecuencia que los dogmáticos jurídicos aboguen que una norma jurídica debe ser descartada por no satisfacer las condiciones mínimas de justicia; esto ocurre sólo en casos muy excepcionales. El procedimiento más usual consiste en argumentar que el legislador no ha previsto el caso en cuestión pues, si lo hubiera previsto, hubiera introducido una distinción relevante que llevaría a una solución diferente... En consecuencia, el dogmático procede a clausurar esta 'laguna', haciendo la distinción relevante y aplicando por analogía alguna otra norma que da una solución más justa. Esto es lo que se ha llamado 'lagunas axiológicas'.

Las lagunas axiológicas son casos con una solución normativa inadecuada. Precisamente, cuando Alchourrón y Bulygin analizan detalladamente estas situaciones usan un ejemplo paradigmático del desarrollo de la doctrina del estado de necesidad: la sentencia del Tribunal del Reich alemán del 11/3/1927, que se refería a la interrupción del

\footnotetext{
${ }^{29}$ Por ejemplo, el artículo 14 de la Constitución Argentina establece: "Todos los habitantes de la Nación gozan de los siguientes derechos conforme a las leyes que reglamenten su ejercicio..."

${ }^{30}$ Bulygin, Eugenio, ‘Dogmática jurídica y sistematización del derecho’ en Alchourrón, Carlos y Bulygin, Eugenio, Análisis lógico y derecho, op. cit., p. 480 (Madrid: Centro de Estudios Constitucionales, 1991)
} 
embarazo por indicación médica en caso de peligro para la vida de la madre ${ }^{31}$. Como es bien conocido, las propiedades que el legislador había valorado como relevantes para resolver esta situación no se ajustaban al caso de un médico que practicó un aborto para impedir que la mujer embarazada se suicidase. La solución del tribunal alemán representó, por consiguiente, una modificación del conjunto de propiedades relevantes para la solución del caso.

La discrepancia con las soluciones que el legislador establece se muestra con claridad en el análisis que Carmen Argibay propone del estado de necesidad. Según el Código Penal Argentino, para que la conducta esté justificada el individuo tiene que ser ajeno al mal grave e inminente que enfrenta. Ante ello, Argibay sostiene ${ }^{32}$ :

Pero no debe llegarse al extremo de descartar de plano el estado de necesidad por la mera actividad precedente del autor.

Así como no podemos exigir al bombero que muera por salvar un mueble, tampoco podría condenarse a quien imprudentemente corre riesgo de ahogarse y, por evitarlo, se apodera de un bote.

Claro está que, ateniéndonos a la estricta letra y exigencia de la norma, siempre podría decirse que la acción típica no está justificada...

En este párrafo pareciera que 'atenerse a la estricta letra y exigencia de la norma' fuese una simple opción interpretativa, un compromiso que pudiese dejarse de lado en 'casos recalcitrantes' en los que surgen conflictos entre las reglas y otras expectativas de justicia ${ }^{33}$. Lo mismo ocurre en el

${ }^{31}$ Alchourrón, Carlos y Bulygin, Eugenio, Introducción a la metodología de las ciencias jurídicas y sociales, pp. 162-163 (Buenos Aires: Astrea, 1974)

${ }^{32}$ Argibay, Carmen, 'Artículo 34, inciso 3. Estado de necesidad justificante' en Baigún, David, et al. Código Penal Comentado, op. cit., p. 630.

${ }^{33} \mathrm{Si}$ lo que el legislador dice expresamente pudiese dejarse de lado, entonces no tendría mayor sentido atribuirle poder normativo a esas autoridades, ni tampoco habría mayor justificación para que sus intenciones y preferencias sean representativas de las intenciones y preferencias de la mayoría. Al respecto, véase, Raz, Joseph, 'Legal Rights', op. cit., p. 251 
Andrés Bouzat - Alejandro S. Cantaro - Pablo E. Navarro

caso de la protección constitucional del domicilio. Puede admitirse que el constituyente no ha dicho todo lo que quería decir, ni ha dicho todo lo que debería decir, pero no hay dudas acerca de lo que efectivamente ha dicho. Por consiguiente, quienes afirman que, en caso de estado de necesidad, es obligatorio o facultativo ingresar a un cierto domicilio (sin que haya consentido su titular o concurran las otras circunstancias enumeradas en el art.18.2 de la CE) tienen que sostener alguna de las siguientes tesis:

a) La constitución no prevalece sobre la legislación ordinaria;

b) Las normas, valores y principios que expresamente ha adoptado el constituyente y sus consecuencias lógicas no agotan el contenido de las normas constitucionales expresamente formuladas;

c) El derecho de necesidad (y su correlativo deber de tolerancia) están sobredeterminados y, junto al fundamento legal que otorga el Código Penal, el derecho de necesidad se encuentra protegido por alguna disposición constitucional.

La estrategia (a) es inviable ya que parece una solución ad hoc y no da cuenta de nuestras instituciones y prácticas. La supremacía constitucional sobre la legislación ordinaria es la que dota de sentido a instituciones específicas como el Tribunal Constitucional, que ratificó en numerosas ocasiones la garantía constitucional de la inviolabilidad del domicilio. Esta supremacía se mantendría incluso si los jueces toman decisiones que reconocen al derecho de necesidad frente a la inviolabilidad del domicilio. Se podría sostener que son decisiones 'constitucionalmente ilegitimas', es decir, que los jueces han decidido de manera definitiva, pero equivocada, sobre las relaciones normativas involucradas ${ }^{34}$. Por

${ }^{34}$ Acerca de la definitividad e infalibilidad de las decisiones de los últimos intérpretes constitucionales, véase: Hart, H.L.A., El concepto de derecho, pp. 176-183 (Buenos Aires: Abeledo Perrot, 1963) 
supuesto, tal vez sea mejor un diseño institucional que permite a jueces y juristas manipular la constitución y cambiar los derechos y garantías que el constituyente establece respecto al que protege la supremacía constitucional, pero hay buenas razones para dudar que éste sea el diseño institucional vigente en nuestras comunidades.

La estrategia (b) lleva a considerar a la constitución como determinada parcialmente por las decisiones de las autoridades y también parcialmente determinada por otras pautas morales que no han sido adoptadas por el constituyente. Hay diferentes versiones de este argumento y no podemos considerarlas detalladamente en este texto. Por ejemplo, Dworkin enfatiza que las cláusulas constitucionales tienen que ser leídas como compromisos morales abstractos y que, por tanto, su contenido no surge del detalle o especificación del constituyente sino de los principios que la justifican ${ }^{35}$.

Por supuesto, no estamos interesados en defender que el derecho es una unidad discreta y desconectada de normas, sin ninguna relación entre sus elementos. Esta idea sería incompatible con una reconstrucción sistemática del derecho. Sin embargo, es preciso subrayar el papel de las

${ }^{35}$ Una analogía puede echar luz sobre dos maneras de comprender el contenido de un cierto material normativo. Supongamos que los derechos constitucionales fuesen como números de teléfono que aparecen en el listado telefónico de una comunidad. Este listado puede tener menos información de la necesaria, i.e. puede ser infra-incluyente acerca del objetivo de hacer públicos todos los números de teléfonos de una comunidad. Si el número de un amigo aparece o no en la guía de teléfono es una cuestión empírica y no depende de las valoraciones e intereses que guíen nuestra búsqueda. Del modo en que está organizado el listado podríamos 'inducir' principios que ordenan la presentación de los números de teléfonos, e.g. la secuencia alfabética, o las calles de los domicilios. A partir de estos principios, del material publicado y de nuestros intereses específicos podríamos inducir que nuestro amigo 'debería' tener un determinado número. Sin embargo, de allí no se sigue que si marcamos ese número nos comunicaremos efectivamente con nuestro amigo. Acerca de la diferencia entre una constitución de principios abstractos y una constitución de normas detalladas, por ejemplo, Dworkin, Ronald, Life's Dominion, pp. 119 y ss (Londres: Harper Collins, 1993) 
Andrés Bouzat - Alejandro S. Cantaro - Pablo E. Navarro

decisiones de las autoridades como fundamento de la verdad de nuestras afirmaciones acerca del derecho. Esta dependencia de las posiciones jurídicas respecto de las decisiones de la autoridad se muestra con claridad, por ejemplo, en una institución fundamental del derecho argentino: el recurso extraordinario ante el máximo tribunal (Corte Suprema de Justicia). Para poder acceder a esta instancia es necesario mencionar expresamente el derecho constitucional vulnerado y el artículo respectivo de la constitución que lo consagra. En caso de que no se cumpla este requisito, el recurso no se considera procedente. De todos modos, quienes sostienen que la Constitución no tiene que ser leída como un listado telefónico sino como un programa moral a desarrollar por los intérpretes, enfrentan algunas complicaciones. La primera dificultad de esta propuesta es que parece arbitrario restringir la incorporación de la moral únicamente a la constitución. Tanto la constitución como otros textos normativos establecen principios, protegen valores y distribuyen cargas y beneficios mediante la asignación de derechos y obligaciones. ¿Por qué razón, entonces, no veríamos también al derecho civil o al derecho penal como parcialmente determinados por las decisiones de las autoridades? En este sentido, ¿por qué limitaríamos los delitos a aquellas fórmulas establecidas por la ley cuando hemos previamente admitido que el contenido del derecho está sólo parcialmente determinado por las decisiones de las autoridades? ¿Por qué insistir en la taxatividad de las normas penales y en la tipicidad de las conductas en el ámbito penal y, en cambio, leer las cláusulas constitucionales de manera abierta? No queremos sugerir que no existan buenas respuestas a esta pregunta sino que ellas no serán de naturaleza lingüística, es decir: no dependerá de la mayor o menor especificidad del lenguaje constitucional sino de nuestras actitudes frente a la constitución y las normas penales. Algunas disposiciones constitucionales son abstractas y necesitan desarrollo, pero otras -como el artículo 18.2 CE- son más específicas que muchas normas del Código Penal.

Una segunda dificultad surge de la naturaleza política del derecho. Dado que con frecuencia no estamos de acuerdo sobre el mejor modo de 
resolver problemas sociales, decidimos establecer un marco de referencia de nuestros acuerdos y desacuerdos para que no sea necesario embarcarnos en una discusión moral cada vez que necesitamos determinar nuestras posiciones jurídicas. Ésta es una función central de las normas jurídicas. Las autoridades prestan un servicio a la comunidad al determinar el esquema de conductas que deben ejecutarse, y ello es posible únicamente cuando los miembros de la comunidad pueden identificar lo que deben hacer sin reabrir el balance de razones que justifica la decisión adoptada por la autoridad ${ }^{36}$. Incorporar como excepciones implícitas a un conjunto abierto de pautas morales relevantes es incompatible con esta función de organización que el derecho pretende cumplir mediante las decisiones de las autoridades.

Finalmente, la estrategia (c) lleva a una reformulación del problema. Para este enfoque, la consagración del derecho de necesidad en el Código Penal no agota sus fundamentos jurídicos. Esto significa que si se eliminase al estado de necesidad de las causas legales de justificación del Código Penal todavía podemos encontrar otra norma, principio o valor constitucional que lo establezca expresamente o implícitamente. Antes de abordar con algún detalle esta opción es conveniente recordar que si el derecho de necesidad se derivase de algún valor constitucionalmente protegido, e.g. la vida, nos encontraríamos con un conflicto de nivel constitucional. En estos casos, la solución no puede ser simplemente establecer un orden jerárquico de carácter general entre ellos. La ponderación de los valores en conflicto sólo puede tener un alcance particular ya que imponer un orden jerárquico es una operación sustancialmente equivalente a la derogación de normas ${ }^{37}$. Si se admitiese que los jueces pueden establecer

\footnotetext{
${ }^{36}$ Acerca de la autoridad como servicio, véase: Raz, Joseph, 'Authority, Law and Morality' en Ethics in the Public Domain, pp. 199-204 (Oxford: Oxford University Press, 1994) ${ }^{37}$ Una refinada presentación de las relaciones entre imponer un orden jerárquico y la eliminación de normas se encuentra en: Alchourrón, Carlos y Makinson, David, 'Hierarchies of Regulations and Their Logic' en Hilpinen, R. (ed), New Studies in Deontic Logic (Dordrecht: Reídle, 1981)
} 
un orden lexicográfico de los valores constitucionales, ello significaría una mutación constitucional y ello excede las atribuciones de los intérpretes constitucionales.

\section{El fundamento jurídico del derecho de necesidad}

La estrategia dominante entre quienes defienden la existencia de un derecho de necesidad y deberes de tolerancia es otorgar a esas posiciones un fundamento diferente (y de mayor nivel) al establecido por las causas de justificación del Código Penal. Esta es también la estrategia que sigue Silva Sánchez en el trabajo que estamos comentando. En principio, Silva Sánchez parece preocupado por hacer explícita la justificación moral para el derecho de necesidad y el deber de tolerancia, y posteriormente, desarrollar su fundamento jurídico. De este modo, señala al inicio de su exposición sobre el fundamento del deber de tolerancia y el estado de necesidad (punto 2.2.)

... la cuestión relativa al fundamento del deber de tolerancia de las conductas realizadas en estado de necesidad agresivo se ha tratado de resolver por remisión a la pregunta sobre la ratio de dicho estado de necesidad.

Sin lugar a dudas, esa línea de análisis conduce a defender argumentos de naturaleza moral. En general, la excusa de estado de necesidad se desarrolló como una expresión del sentimiento moral de compasión frente a individuos que se encontraban en situaciones difíciles. Al transformarse la situación de necesidad en causa de justificación es preciso encontrar un fundamento más sólido. Luego de descartar las posiciones utilitaristas, Silva Sánchez subraya que la razón de la justificación del estado de necesidad se encuentra ligada al principio moral de solidaridad.

... por lo común se alude a que el fundamento del estado de necesidad agresivo -y, por añadidura, del deber de tolerancia de terceros- se halla en el principio de solidaridad. Partiendo de que éste muestra, de entrada, una naturaleza moral, se 
ha intentado explicar su juridificación desde perspectivas, por un lado, contractualistas y, por el otro, institucionalistas.

Este último párrafo concede con claridad la diferencia entre el reconocimiento de un principio moral y su 'jurídificación', es decir, el modo en que se plasma en el derecho positivo y puede ser invocado por los jueces para justificar sus decisiones. Esto significa que no puede sostenerse que los ciudadanos tienen un derecho jurídico de necesidad y un correlativo deber jurídico de tolerancia porque existe un deber moral de ayudar al prójimo. A menos que esta pauta moral haya sido adoptada por el legislador, su existencia es completamente irrelevante para decidir controversias jurídicas. En otras palabras, si no se muestra el modo en que se ha 'juridificado' el principio moral de solidaridad en un determinado ordenamiento jurídico, entonces los argumentos tienen que ser entendidos como afirmaciones acerca de los derechos y deberes que los individuos deberían tener en un sistema jurídico moralmente decente. En este caso, los argumentos serían una crítica de las instituciones vigentes y un buen alegato a favor de la reforma del derecho.

Dada la importancia de la fundamentación jurídica se podría esperar un análisis minucioso de las normas y principios jurídicos involucrados en el estado de necesidad y el deber de tolerancia. Sin embargo, Silva Sánchez se limita a unas indicaciones genéricas sobre este problema, en las que adhiere a las nuevas concepciones institucionalistas. El rasgo distintivo de estas doctrinas sería que se extrae la idea de solidaridad 'de la esfera del ámbito del mundo de la vida y se la configura desde dentro del propio sistema jurídico-político'. Como exponentes contemporáneos de esta alquimia se mencionan a Jakobs y Pawlik. Conforme a la reconstrucción ofrecida por Silva Sánchez (ver en su trabajo el punto 2.2. sobre el fundamento del deber de tolerancia y estado de necesidad, pp. 33 y ss.), Jakobs fundamenta

... el estado de necesidad agresivo y el deber de ayuda en situaciones de necesidad en que "el citoyen se tiene que ocupar de lo general", lo que presupone, más 
Andrés Bouzat - Alejandro S. Cantaro - Pablo E. Navarro

allá de una sociedad civil, "la existencia de relaciones públicas justas, es decir, un orden estatal". En otras palabras, sosteniendo que "de la idea de responsabilidad política de todos los ciudadanos se deduce el derecho y el deber de actuar para el Estado en casos de desastre sacrificando bienes de escaso valor o soportando ese tipo de acciones". Esta misma idea ha sido desarrollada extensamente por Pawlik, para concluir que es posible atribuir al individuo, como parte integrante de su posición de ciudadano, el deber de soportar en casos excepcionales la injerencia de terceros en la propia esfera jurídica.

Una norma que reconozca el derecho de necesidad sólo puede derivarse de otra norma y no de ideas, conceptos, definiciones o proposiciones. Por ello, es crucial preguntar: ¿de qué norma se deriva el derecho de necesidad? En el argumento atribuido a Jakobs parece asumirse que hay una cierta norma $\mathrm{N}$ que establece: "Los ciudadanos deben ocuparse de lo general" y de esa norma se seguiría otra que impone tolerar las conductas de quienes se encuentran en estado de necesidad. Pero, esta respuesta inmediatamente lleva a preguntar acerca del status jurídico de estas normas. Como señala Joseph Raz ${ }^{38}$,

En los casos en que la justificación parte de premisas no jurídicas, resulta claro que no puede establecer la verdad de un enunciado jurídico, ni la validez de una norma jurídica. En el mejor de los casos, forma parte de un argumento a favor de su conveniencia.

Podemos preguntarnos, entonces: ¿acaso el legislador ha formulado estas normas? La respuesta es contingente y depende de las decisiones del legislador. Por supuesto, nada impide que la autoridad establezca obligaciones genéricas para los ciudadanos y que una norma como $\mathrm{N}$ haya sido expresamente adoptada en alguna comunidad. Por ejemplo, el artículo 21 de la Constitución Argentina establece: "Todo ciudadano argentino está obligado a armarse en defensa de la patria y de esta

${ }^{38}$ Raz, Joseph, 'Legal Rights' en Ethics in the Public Domain, op. cit., p. 247 
constitución...”. Ello muestra que no existe impedimento alguno para que se impongan expresamente deberes a todos los ciudadanos. Pero, sin embargo, la norma que impone el deber de tolerancia no se encuentra en la Constitución Argentina (o en la Española), y no parece sencillo indicar en las propuestas de Jakobs o Pawlik qué normas habría que eliminar del sistema jurídico para que desapareciesen esos derechos y deberes.

\section{Derecho de necesidad y cuasi-instituciones}

Es momento ahora de analizar la propuesta específica de Silva Sánchez. Conforme a nuestro autor (punto 2.2. sobre el fundamento del deber de tolerancia y estado de necesidad, pp. 34):

La idea central, que me interesa resaltar, es que en el Estado moderno no cabe admitir que la distribución social de suerte y desgracia sea cosa de la naturaleza, sino que, en cierta medida, es al Estado a quien corresponde la corrección de esa distribución. Ello tiene lugar, en general, a través de instituciones públicas organizadas. Sin embargo, en ocasiones, éstas pueden llegar demasiado tarde; y es en este punto en el que surgen "derecho de necesidad" y "deber de tolerancia" como "cuasi-instituciones" subsidiarias.

El deber de tolerancia aparece, en suma, como un deber cuasi-institucional dinámico, cuya función es contribuir a asegurar las condiciones reales de la libertad jurídica en aquellas situaciones límite a las que no alcanzan las medidas institucionales ordenadas de modo estático a subvenir a las necesidades de los ciudadanos.

Con este párrafo, Silva Sánchez agota su análisis de la fundamentación jurídica del derecho de necesidad y el deber de tolerancia. Más allá de que este párrafo no identifica ninguna norma que pueda ser eliminada $y$, de esta manera, se pueda invocar como el fundamento explícito del derecho de necesidad y el deber de tolerancia, sus premisas tampoco parecen incontrovertibles. Por ello, es especialmente relevante un análisis detallado de este breve párrafo. 
a) Los Estados modernos y la corrección de las suertes y desgracias

El derecho cumple con la función de distribuir 'suertes y desgracias' mediante la asignación de derechos, cargas y beneficios ${ }^{39}$. Las autoridades valoran necesidades y recursos sociales y, mediante sus normas, intentan conservar o modificar esas situaciones. Pero, de allí no se sigue, sin embargo, que la corrección de suertes y desgracias en el Estado moderno tenga que ser efectuada inevitablemente de una manera específica o que persiga fines determinados. Más bien, esta corrección depende del modo en que se asignan recursos sociales y ello está regulado en las normas jurídicas, que reflejan compromisos políticos y morales centrales en una cierta sociedad. Por ejemplo, una sociedad con convicciones ultra-liberales puede considerar que la compasión frente a los que enfrentan dificultades o la ayuda al que padece necesidad es un rasgo solamente meritorio de nuestra conducta y que el Estado debe abstenerse de cumplir funciones redistributivas.

A su vez, las instituciones mediante las que el Estado interviene en la comunidad son constituidas por normas jurídicas de una enorme heterogeneidad, i.e. administrativas, penales, tributarias, etc. Si se acepta que el Estado interviene en la corrección de suertes y desgracias conforme a parámetros legales previamente establecidos, entonces hay también una buena razón para creer que el derecho de necesidad y los deberes de tolerancia dependen de lo que establece el derecho y no de la función moral de corrección de la distribución de cargas y beneficios. Por ejemplo, en el derecho argentino sólo se encuentra justificado quien causa un mal para evitar otro mal mayor e inminente al que ha sido ajeno, mientras que otros diseños institucionales pueden enunciar exigencias diversas (por ejemplo, pueden exigir una considerable desproporción en los bienes ponderados).

\footnotetext{
39 Joseph Raz se refiere a esta característica como una función social directa y primaria del derecho. Véase, Raz, Joseph, 'The Functions of Law' en The Authority of Law, op. cit., pp. 1979.
} 
Por consiguiente, el alcance y fuerza del 'estado de necesidad' no es una situación natural que pueda abordarse mediante cuasi-instituciones sino una situación específicamente determinada por las normas que lo regulan. El hecho bruto de la 'necesidad' no es lo que fundamenta jurídicamente la legitimidad de ciertas conductas sino más bien es el modo en que el legislador define al 'estado de necesidad' lo que cuenta para evaluar si una conducta se encuentra justificada.

b) Cuasi-instituciones y naturaleza subsidiaria de los derechos de necesidad

El carácter subsidiario del derecho de necesidad se justifica en la imposibilidad de que el Estado intervenga a tiempo en su tarea de corregir suertes y desgracias. Conforme a esta idea, el Estado reconocería un 'estado de necesidad' sólo cuando la intervención de sus instituciones fuese extemporánea o imposible. Como señala Carmen Argibay ${ }^{40}$,

El fundamento de la justificación es que no puede evitarse aquella situación de peligro grave e inminente por otro medio que no sea causar un daño a otro bien ajeno. O, como diría la sabiduría popular, 'la necesidad tiene cara de hereje'. No puede esperarse la usualmente lenta reacción del Estado, ni el derecho puede pretender que la persona se cruce de brazos frente al peligro para un bien o interés jurídico, propio o ajeno, de mayor valor que el afectado en definitiva.

La idea de que el fundamento del estado de necesidad es la imposibilidad de que el Estado 'llegue a tiempo' con sus instituciones tiene un notable arraigo. Así, por ejemplo, en 1993, un fallo de la Cámara Nacional en lo Criminal y Correccional señaló que la conducta de un individuo que robaba para atender la enfermedad de su hija no estaba encuadrada en el supuesto del estado de necesidad ya que, para atender

\footnotetext{
${ }^{40}$ Argibay, Carmen, 'Artículo 34, inciso 3. Estado de necesidad justificante’ op. cit., pp $627-628$
} 
esas enfermedades, existían hospitales públicos que gratuitamente proveían de atención y medicinas ${ }^{41}$.

Aunque esta relación entre el carácter subsidiario del derecho de necesidad y la imposibilidad de la intervención eficaz de las instituciones estatales captura las situaciones que paradigmáticamente se encuadran dentro del estado de necesidad, es conveniente señalar dos dificultades a este fundamento. El primer inconveniente es su alcance limitado, que deja sin cobertura a situaciones que no ofrecen diferencia moral relevante con las justificadas. El segundo problema es el resultado contra-intuitivo que surge de la proyección de esos fundamentos a otras situaciones diferentes.

Atribuir un carácter subsidiario a la justificación de las conductas que se emprenden en estado de necesidad puede restringir de manera moralmente arbitraria el alcance de la justificación. Por ejemplo, un buen samaritano puede colaborar con una institución, e.g. los bomberos, en un rescate, sin que su intervención sea necesaria. Supongamos que en su desempeño causa un cierto daño en una vivienda para cooperar en el salvamento de una persona. Si el derecho de necesidad sólo ampara a individuos que reaccionan cuando las instituciones estatales no llegan a tiempo, entonces hay que concluir que el buen samaritano no se encuentra justificado en su conducta. Es conveniente destacar que este aspecto subsidiario no es exigido en la formulación de las causas de justificación que se encuentra en diversos Códigos. Así el Código Penal Argentino no requiere que la actuación de las instituciones jurídicas sea imposible, o que lleguen con retraso, sino únicamente que se sacrifique un bien de menor valor para evitar un mal inminente y grave. Por consiguiente, es necesario remarcar una vez más que se precisa trazar una clara distinción entre la eventual justificación moral del estado de necesidad y su caracterización jurídica. Del hecho de que sepamos por qué hay que reconocer como causa de justificación al estado de necesidad no se sigue

${ }^{41}$ CNCriminal y correccional, Sala I, 18/10/1993. 
que también conozcamos qué conductas se encuentran justificadas. En el primer caso se requiere conocimiento moral y en el segundo se precisa de conocimiento del derecho.

En segundo lugar, la fundamentación del derecho de necesidad conduce a resultados contra-intuitivos cuando se generaliza a otras situaciones e instituciones. Si aquello que justifica apropiarse de bienes de otros individuos es que el Estado moderno no interviene a tiempo en la corrección de suertes y desgracias, entonces sería útil proyectar esta solución a problemas que surgen con otras funciones que cumple el Estado. En otras palabras, parece arbitrario admitir que la lentitud del Estado en la corrección de suerte y desgracia justifica intervenir en bienes ajenos y negarse a admitir esa conclusión para otras dimensiones de la actividad estatal.

Una función social importante que cumple el derecho, a través de las instituciones estatales, es la solución de conflictos. En general, esta función es cumplida por jueces y tribunales mediante la aplicación de normas jurídicas. Sin embargo, al igual que ocurre con otras instituciones estatales, la actuación de los jueces puede ser ineficiente y llegar tarde para proteger derechos y resolver controversias. Ello genera una sensación de frustración social y deseos de administrar justicia 'por mano propia'. ¿Serían estas premisas suficientes para sostener que, en caso de que el Estado no llegue a tiempo a la solución de la controversia, surgen cuasi-instituciones donde los individuos tienen derecho a aplicar las normas y sus semejantes tienen el deber de someterse a sus actos cuasi-jurisdiccionales? La institución de la legítima defensa parece sugerir una respuesta afirmativa a esta pregunta. Sin embargo, ¿estaríamos dispuestos a generalizar esta respuesta, admitiendo que cuando los tribunales no desempeñan de manera satisfactoria su tarea, los individuos pueden ejercer funciones jurisdiccionales? Si la respuesta es negativa, entonces también hay buenas razones para dudar acerca de la existencia de un derecho jurídico de necesidad y de un correlativo deber de tolerancia por el mero hecho de que el Estado no llegue a tiempo con su función de corrección de suerte y desgracia. 
Andrés Bouzat - Alejandro S. Cantaro - Pablo E. Navarro

El reconocimiento de que el derecho de necesidad y los deberes de tolerancia son cuasi-instituciones todavía no explica por qué ellos generan derechos y deberes efectivos en lugar de semi-derechos o semi-obligaciones. La fuerza jurídica de los derechos y deberes se muestra en el modo en que requiere la intervención de las instituciones jurídicas y ello significa que la relevancia jurídica de la cuasi-institución del estado de necesidad sólo puede ser apreciada en el marco de instituciones. Como señala Fletcher, estas cuestiones surgen ${ }^{42}$

En un sistema de justicia espontánea, tal como la práctica de ejecutar ladrones nocturnos, no hay lugar para un sistema de excusas. La eventualidad del castigo privado se apoya únicamente en el efecto incriminador de las apariencias. Las excusas de error, accidente, necesidad e insania comienzan a desarrollarse sólo en tanto que el proceso de condena a sufrir castigos se mueve desde la escena de los hechos a la meditada deliberación de los tribunales.

\section{EI contenido normativo del deber de tolerancia}

El deber de socorro directo, y hasta de colaboración activa con la actuación del necesitado, es un deber jurídico que, por lo general, surge de normas específicas de los diferentes códigos penales modernos. De esas normas se sigue un deber negativo de no interrumpir la conducta salvadora de quien se encuentra en estado de necesidad. Sin embargo, si el afectado por la conducta del necesitado se mantiene en su esfera jurídica originaria, neutralizando la conducta del necesitado, no puede decirse que haya infringido un deber jurídico especial. A menos que exista otra norma especifica, que imponga una posición de garantía de la que deriven especiales deberes de evitar un resultado típico, el afectado que no colabora con la conducta salvadora sólo ha infringido las normas relativas al deber de socorro.

No es posible analizar aquí exhaustivamente el problema de la omisión, los cursos salvadores y las condiciones bajo las que es posible

\footnotetext{
${ }^{42}$ Fletcher, George, Rethinking Criminal Law, pp. 759-760 (Oxford: Oxford University Press, 2000)
} 
atribuir responsabilidad ${ }^{43}$. Sólo remarcaremos que el artículo 11 del Código Penal Español requiere, para que se atribuya la producción del resultado típico a una cierta omisión, la verificación de que el sujeto se encuentra en una posición de garante. La mera violación de un deber moral no puede fundamentar el reproche: sólo cuando se infringen deberes específicos de actuar, impuestos por el orden jurídico, surge esa posición de garante y se puede atribuir responsabilidad por el resultado típico ${ }^{44}$. La equivalencia entre omisión y comisión siempre debe ser interpretada en el sentido en que lo impone la ley ${ }^{45}$. Por tanto, los casos de injerencia que no fundamenten equivalencia plena de la omisión subsiguiente con la comisión activa sólo pueden ser castigados como infracción al deber de auxilio (omisión de socorro). Al igual que otros deberes jurídicos, la posición de garante también debe responder a decisiones taxativas del legislador. Por tanto, el artículo 11 incisos a) y b) del Código Penal Español, que refiere a la equiparación de la omisión a la acción, no tiene un carácter meramente ejemplificativo ya que ello implicaría reconocer deberes jurídicos que carecen de fuentes penales expresas ${ }^{46}$. Precisamente, en el

${ }^{43}$ Una discusión de este problema llevaría a un análisis exhaustivo de las tesis defendidas por Silva Sánchez en El delito de omisión. Concepto y sistema, pp. 216 y ss (Barcelona: Bosch, 1996)

44 “Artículo 11: Los delitos o faltas que consistan en la producción de un resultado sólo se entenderán cometidos por omisión cuando la no evitación del mismo, al infringir un especial deber jurídico del actor, equivalga, según el sentido del texto de la Ley, a su causación. A tal efecto se equiparará la omisión a la acción: a) Cuando exista una específica obligación legal o contractual de actuar. b) Cuando el omitente haya creado una ocasión de riesgo para el bien jurídicamente protegido mediante una acción u omisión precedente".

${ }^{45}$ Silva Sánchez señala, con espíritu crítico, que el modo en que el Código Penal español regula la omisión habría desplazado el centro de gravedad del análisis desde la constatación de la identidad estructural desde perspectivas normativo-materiales, a la constatación de un deber jurídico específico. Silva Sánchez, Jesús-María: "Consideraciones sobre la teoría del delito", p. 92 (Buenos Aires: Ad Hoc, 1998)

${ }^{46}$ Por el contrario, Silva Sánchez defiende un carácter meramente ejemplificativo en Silva Sánchez, Jesús-María: “Consideraciones sobre la teoría del delito”, op. cit., p. 95. 
inciso b del artículo 11 del Código Penal, el legislador ha decidido ligar la atribución de responsabilidad con la creación de un determinado riesgo. En este sentido, el afectado debe haber creado, con un actuar previo peligroso, una ocasión de riesgo para el bien protegido. El afectado debe haber colocado a otra persona en una situación de riesgo de la que ésta no pudiere salir sin la ayuda de aquella. En este caso, surge para el causante del peligro un deber de actuar para evitar el resultado ${ }^{47}$.

En su trabajo Silva Sánchez (punto 5.1.) advierte que entre la infracción del deber de tolerancia y la producción del resultado lesivo no existe relación de causalidad y ello equivale a admitir que esas infracciones no crean el riesgo relevante. Sin embargo, concluye del siguiente modo:

... me parece difícil negar que quien interrumpe un curso causal salvador ajeno -aquí, el sujeto que no tolera la conducta realizada en estado de necesidad agresivoproduce un incremento del riesgo de producción del resultado lesivo que amenaza al sujeto necesitado...En mi opinión, ello implica que el sujeto que infringe el deber de tolerancia se convierte en garante de aseguramiento del riesgo incrementado, que queda integrado en su esfera de organización.

Un desarrollo de esta tesis debe superar las siguientes dificultades. En primer lugar, aun cuando la infracción al deber de tolerancia

\footnotetext{
${ }^{47}$ En el proceso legislativo argentino se tuvo en cuenta que una de las fuentes de garantía podría ser la actuación precedente o la injerencia; el Anteproyecto de 1960 aludía en su art. 10: “.... a quien tenga por ley, obligaciones de cuidado, protección o vigilancia; a quien con su comportamiento precedente creó el riesgo, y a quien, asumiendo la responsabilidad de que el resultado no ocurriera, determinó con ello que el riesgo fuera afrontado". Asimismo, el Proyecto de 1973, en su art. 14, aludía a quien: "...le incumbía el deber jurídico de cuidar que ese resultado no se produjera o cuando el riesgo que originara el resultado se hubiera creado con su comportamiento precedente". El Proyecto de 1979 establecía en el art. 10 que el "...deber de obrar incumbe a quien tenga una obligación especial de cuidado, protección o vigilancia derivada:... c) de una actuación precedente que comporte la asunción unilateral de alguna de aquellas obligaciones; d) de una actuación precedente que haya creado el riesgo inminente de que ocurriera el resultado".
} 
incrementase el riesgo de que se produzca un resultado disvalioso, la ley señala como responsable sólo a quien ha creado un riesgo y no menciona el caso del incremento del riesgo, como fuente del deber de garante. En segundo lugar, el incremento del riesgo en una cierta ocasión es una cuestión empírica y no es posible asumir que la infracción del deber de tolerancia tenga siempre esa consecuencia. Por ejemplo, A necesita con urgencia un vehículo para comprar medicinas para su ganado enfermo y puede escoger entre la bicicleta de su vecino B y el auto de su vecino C. Cualquiera de estos vehículo serviría para que A obtenga la finalidad que persigue. Supongamos que al pedir prestada la bicicleta, B se niega a entregársela y le recuerda que $\mathrm{C}$ tiene un automóvil, y que con ese vehículo cumplirá de manera más apropiada con su plan salvador. Podría sostenerse que, aun cuando B se ha negado a cooperar y ha privado a su vecino de un medio idóneo para su curso salvador, su negativa aumenta la probabilidad de evitar un resultado disvalioso ya que el automóvil es un vehículo más eficiente para resolver la situación de urgencia.

Por último, la tesis de Silva Sánchez parece conducir a un resultado contra-intuitivo. Si se tomase a esa propuesta como base de la imputación objetiva de la conducta, ella impondría responsabilidad al autor en casos en que se hubiera producido el resultado vinculado al riesgo, pero no podría probarse que ese resultado sea una consecuencia del comportamiento que interrumpe el curso salvador ${ }^{48}$.

\section{Cláusulas de ajuste en derecho penal}

Un rasgo central de las normas válidas es que ellas provocan una 'diferencia práctica', es decir, las razones para actuar de los individuos se

\footnotetext{
48 Para Jakobs, '...la teoría del incremento del riesgo constituye un instrumento imprescindible para la definición del comportamiento no permitido pero inidóneo para aportar algo sobre la relación de finalidad de la norma entre acción y resultado.' Jakobs, Günther, Derecho Penal, Parte General, p. 287 (Madrid: Marcial Pons, 1995)
} 
Andrés Bouzat - Alejandro S. Cantaro - Pablo E. Navarro

modifican con su presencia o ausencia. Este rasgo sirve para distinguir entre diferentes niveles de normas en un sistema penal. Una norma de primer nivel es la que impone un deber jurídico específico, e.g. la que prohíbe el homicidio, el estupro, el infanticidio, el hurto, etc. Estas son las normas 'genuinas' del sistema ya que imponen específicamente una solución y su desaparición provoca una notoria diferencia en la atribución de responsabilidad. Por ejemplo, al desaparecer la figura del infanticidio en el derecho penal argentino, la muerte del recién nacido por parte de su madre pasa a ser un homicidio calificado por el vínculo. En igual sentido, si desapareciesen del Código Penal todas las figuras delictivas, con excepción de -por ejemplo- el homicidio y el hurto, todavía sería verdad que, en ese sistema mínimo, está prohibido matar a otro y apoderarse de bienes muebles ajenos. En cambio, no tiene sentido preguntarse acerca de qué conductas se encuentran prohibidas si en el Código Penal sólo hubiese disposiciones relativas a la tentativa, la participación, o causas de justificación. Éstas son normas de segundo nivel y son conceptualmente dependientes ya que su función es corregir el alcance y la fuerza de las normas de primer nivel.

El modo en que están redactados los Códigos modernos impone, por lo general, un resultado específico, que constituye el evento disvalioso al que se liga la atribución de responsabilidad. La identificación de este resultado mediante fórmulas escritas relativamente breves provoca un desajuste entre lo que se dice que se reprocha y lo que se debería reprochar. Cualquier norma genera casos recalcitrantes de infra-inclusión y de sobre-inclusión respecto a las razones que la justifican, y estos desajustes son corregidos por diferentes cláusulas del Código Penal. Por ejemplo, las causas de justificación previenen la sobre-inclusión de las normas penales, ofreciendo razones de principio para no castigar ciertas conductas típicas. Otras cláusulas de ajuste tienen la función de incluir en el ámbito de reproche a conductas que no están descriptas en el tipo penal, pero que merecen castigo a la luz de los principios que justifican las normas del sistema. Ejemplos paradigmáticos de estas cláusulas de 
ajuste, que pretenden corregir la infra-inclusión de los tipos penales específicos, son las normas referidas a la tentativa y la participación. Estas normas dependen de otras normas de la parte especial de los Códigos en dos sentidos diferentes. Por una parte, la desaparición de las normas de la parte especial privaría de sentido a esas cláusulas de ajuste $\mathrm{y}$, por otra parte, la pena que se atribuye a las conductas incluidas en el ámbito de reproche por las cláusulas de ajuste depende de la sanción prevista en cada delito en particular.

La naturaleza legal o supra-legal de esas cláusulas de ajuste ha sido extensamente debatida en el ámbito de las causas de justificación. Por el contrario, el trabajo de Silva Sánchez acerca de la infracción de deberes de tolerancia es un buen ejemplo de una cláusula de ajuste supra-legal que tiene por función incluir en el ámbito de reproche a conductas que el legislador no ha considerado expresamente. A diferencia de lo que ocurre con la tentativa o la participación, los deberes de tolerancia no están expresamente recogidos en los modernos Códigos Penales. La infracción al deber de tolerancia aparece, entonces, como una cláusula genérica de ajuste, que permite corregir la infra-inclusión de los tipos penales, mediante la creación dogmática de un deber genérico de garante. El deber de tolerancia no introduce nuevos delitos que pueda cometer un determinado sujeto sino que es una suerte de deber genérico de no infringir otras normas del Código Penal (e.g. la omisión de socorro u otras figuras específicas).

\section{$X$. Acerca de las normas dogmáticas}

El modo en que Silva Sánchez expone el fundamento del derecho de necesidad y el deber de tolerancia sugiere una profunda diferencia con el enfoque que hemos usado en este trabajo para dar cuenta del significado y valores de verdad de los enunciados jurídicos. En general, podría sostenerse que para nosotros un fundamento jurídico es siempre un elemento del derecho positivo (e.g. una norma), y la labor central de la dogmática es identificar y sistematizar este material. Por el contrario, 
Silva Sánchez - y muchos otros penalistas - van más allá de las decisiones del legislador en la justificación de sus afirmaciones y su visión de la dogmática no se limita a identificar y desarrollar las normas positivas ${ }^{49}$. Más bien, para este enfoque, la 'verdadera misión' de la dogmática es ofrecer nuevas soluciones a casos que el legislador no ha resuelto y, en ocasiones, corrige el modo en que la autoridad ha regulado una cierta situación $^{50}$. Ello implica introducir nuevas normas en el sistema jurídico ya que sólo de esa manera se pueden lograr regular situaciones que no habían sido contempladas o modificar las relaciones jurídicas establecidas previamente por el legislador. En el caso del estado de necesidad son esas nuevas normas las que se invocan como fundamento del derecho de necesidad y deber de tolerancia. Por razones de simplicidad, denominaremos a estas normas como 'normas dogmáticas' y sus características más destacadas son las siguientes:

a) Las normas dogmáticas son formuladas por individuos que carecen de autoridad política;

b) En tanto que el rango de una norma es una función del nivel de la autoridad, las normas dogmáticas carecen de jerarquía específica;

c) Dado que la jerarquía de una norma determina qué autoridad puede eliminarla del sistema, las normas dogmáticas son ajenas al procedimiento normal de modificación de los sistemas, i.e. derogación expresa o tácita.

Cada uno de estos rasgos de las normas dogmáticas es un desafío a ideas básicas acerca del derecho. En este sentido, la dogmática contemporánea se enfrenta a tres problemas diferentes:

\footnotetext{
${ }^{49}$ Véase, por ejemplo, Roxin, Claus, 'Sobre la significación de la sistemática y dogmática del derecho penal' en Política criminal y estructura del delito, pp. 35-63 (Barcelona: PPU, 1992)

${ }^{50}$ Silva Sánchez, Jesús-María, Aproximaciones al derecho penal contemporáneo, p. 42 (Barcelona: Bosch, 1992); Bacigalupo, Enrique, Delito y punibilidad, $2^{\mathrm{a}}$ edición, pp. 43 y ss (Buenos Aires: Hammurabi, 1999)
} 
- Legitimidad: las obligaciones impuestas por normas que no emanan de autoridades políticamente responsables carecen de legitimidad,

- Estructura: la introducción de normas dogmáticas diluye la estructura jerárquica del sistema jurídico,

- Especificidad: se pierde la especificidad de la fuerza institucional de las normas jurídicas ${ }^{51}$.

No queremos sostener que la dogmática contemporánea no pueda resolver estos problemas, sino que la elaboración de sus soluciones no ocupa un lugar central en su agenda de discusión y que un análisis completo de los derechos de necesidad y los deberes de tolerancia tiene que ofrecer una respuesta a estos problemas.

\section{Conclusiones}

En este trabajo hemos sostenido que la calificación jurídica de una conducta surge de normas jurídicas y que uno de los rasgos principales de estas normas es que pueden ser deliberadamente eliminadas del sistema normativo. Esta característica es la que permite dar sentido a dos ideas centrales de la teoría del derecho. Por una parte, la relatividad de los enunciados jurídicos. Conforme a esta reconstrucción, puede ser verdad que una cierta acción está prohibida en un sistema S1 y, a la vez, puede ser falso que ella esté prohibida en otro sistema S2. Por otra parte, no hay normas 'necesarias' en los sistemas jurídicos. Las normas jurídicas son

\footnotetext{
${ }^{51}$ A diferencia de la fuerza moral de una norma, que es una función de su corrección sustantiva, la fuerza institucional depende de la resistencia al cambio, modificación o eliminación en un sistema jurídico. Al respecto, véase: Waluchow, W.J., Inclusive Legal Positivism, pp. 31-79 (Oxford: Oxford University Press, 1994), Navarro, Pablo et al, 'La fuerza institucional del derecho' en Revista de la Facultad de Derecho, UNAM, 53, número 241, pp. 187-209
} 
aquellas que el legislador ha 'puesto' expresa o implícitamente en un sistema jurídico. Nuestro análisis conduce a la siguiente conclusión: dado que las normas jurídicas son 'contingentes', nada impide que los derechos de necesidad y los correlativos deberes de tolerancia hayan sido establecidos en un determinado sistema. En esos casos, su nivel jerárquico depende del rango de la autoridad que lo ha consagrado y sólo esas autoridades (y otras de rango superior) pueden suprimirlos. Pero, si esos derechos y deberes no han sido expresamente reconocidos y no se derivan de otras normas explícitamente formuladas, entonces ellos no forman parte de las posiciones jurídicas que asegura un determinado sistema jurídico.

Nuestro enfoque llega a conclusiones diferentes a las que sostiene Silva Sánchez. En general, nuestras discrepancias surgen en torno de los criterios para identificar normas implícitas en un cierto sistema. En este trabajo, sólo hemos usado las reglas de inferencia clásicas para determinar las consecuencias de las normas formuladas por la autoridad. Silva Sánchez, al igual que otros dogmáticos, recurre a proposiciones implícitas y reglas adicionales. Por esta razón no siempre es fácil evaluar la solidez de sus premisas y controlar la corrección de sus inferencias.

En gran medida, creemos que los problemas de su reconstrucción son una consecuencia directa del abandono de la separación entre la descripción y la crítica del derecho positivo. La creencia de que las normas dogmáticas ya son parte del derecho borra la distinción entre el derecho que es y el que debe ser, y conduce a una confusión entre los derechos jurídicos y morales. Probablemente, el error de este enfoque surge de una interpretación equivocada del aspecto dinámico de los derechos. Como señala $\operatorname{Raz}^{52}$,

Una parte importante de nuestra comprensión de los derechos jurídicos radica en captar sus consecuencias lógicas. Estas son, como hemos visto, las que justifican jurídicamente otros derechos y deberes. Algunos de ellos reciben su fuerza vinculante de esta justificación. Otros serán deberes y derechos jurídicos

${ }^{52}$ Raz, Joseph, ‘Legal Rights’, op. cit., p. 253 
establecidos por fuentes jurídicas independientes. Algunos otros no son todavía jurídicamente vinculantes. Estas últimas consecuencias de los derechos jurídicos merecen especial atención, ya que demuestran que los derechos jurídicos constituyen razones jurídicas para otorgar fuerza jurídica a los derechos y deberes justificados. Establecen el aspecto dinámico de los derechos. Los derechos jurídicos pueden ser razones jurídicas para el cambio en el derecho. Los derechos jurídicos pueden constituir fundamentos para desarrollar el derecho en una determinada dirección. En virtud de su aspecto dinámico, los derechos jurídicos no pueden reducirse, como se ha sugerido a menudo, a los deberes jurídicos que justifican. El hacerlo equivale a olvidar su papel como razones para la modificación y el desarrollo del derecho.

Esta separación entre descripción y crítica del derecho fue no sólo una división metodológica fundamental sobre la que se construyó la moderna ciencia del derecho penal sino que también fue una de las piezas decisivas en las reformas jurídicas y sociales logradas en la construcción de un Estado de Derecho ${ }^{53}$. Es difícil encontrar una obra que reconozca de modo tan tajante la separación entre descripción y crítica del derecho y que, a la vez, haya ejercido una influencia tan profunda como el libro de Beccaria sobre los delitos y las penas ${ }^{54}$. Por ello, no es casual que Jeremy Bentham considerase que ${ }^{55}$,

...Beccaria fue el primero en embarcarse en la crítica del derecho y en abogar por reformas sin confundir su tarea con la descripción del derecho existente.

${ }^{53}$ Hart, H.L.A., 'Positivism and the Separation of Law and Morals' en Essays in Jurisprudence and Philosophy, p. 51 (Oxford: Oxford University Press, 1983)

${ }^{54}$ Una breve información de esta influencia puede encontrarse en la introducción de Francisco Tomás y Valiente al libro de Beccaria. Véase: Tomás y Valiente, Francisco, 'Introducción' en Beccaria, Cesare, De los delitos y las penas, pp. 15-16 (Buenos Aires: Orbis, 1984)

${ }_{55}^{5}$ Hart, H.L.A., 'Bentham and Beccaria' en Essays on Bentham, p. 41 (Oxford: Oxford University Press, 1982) 
Andrés Bouzat - Alejandro S. Cantaro - Pablo E. Navarro

Beccaria nunca pretendió que las reformas que proponía ya eran derecho, en algún sentido trascendental, o ‘el verdadero derecho'; y así trazaba una distinción que el mismo Bentham continuamente subrayaba entre lo que el derecho es y lo que debe ser, o como Bentham llamaba a menudo, entre la 'teoría del derecho expositiva' y la 'crítica del derecho' (censorial jurisprudence)... Por ésta y otras razones, Bentham se refería a que Beccaria sería recibido por un individuo inteligente como un ángel del cielo sería recibido por un creyente.

Al margen de esta discrepancia metodológica central acerca del conocimiento del derecho y la naturaleza de la dogmática, no podemos dejar de señalar que el trabajo de Silva Sánchez aborda muchos otros temas que no hemos mencionado aquí. En particular, su análisis conecta de manera clara y novedosa problemas de dogmática penal sobre el estado de necesidad justificante con cuestiones de diversa índole: (a) discusiones de filosofía política y moral sobre la relevancia de la solidaridad como fundamento de deberes morales, la justificación de la propiedad privada, etc.; (b) problemas epistemológicos clásicos sobre las relaciones entre omisiones y cursos causales; (c) aspectos centrales de la teoría jurídica como, por ejemplo, la naturaleza de los derechos. Todas estas cuestiones merecen una detallada discusión y muestran la riqueza y fecundidad de su trabajo. 